\title{
The Emergence of Two Functions for Spatial Devices in Nicaraguan Sign Language
}

\author{
Ann Senghas \\ Barnard College of Columbia University, New York, N.Y., USA
}

\section{Key Words}

Language birth $\cdot$ Language change $\cdot$ Language emergence $\cdot$ Spatial language

\begin{abstract}
The emergence of a new sign language since the late 1970s in Nicaragua enables us to capture the effects of successive cohorts of learners on an emerging grammar and to observe how elements are reshaped from one form and function to another. Here we document the contrastive use of a device that has been found to be central to the grammars of sign languages: the spatial modulation of signs. In Nicaraguan Sign Language, this device has two primary functions: expressing the participants of events (that is, indicating who), and describing locations and orientations of referents (that is, indicating where). We ask whether the two uses reduce to a single construction type, or if the more abstract who construction derived from the more iconic and concrete where construction. We compare the first two successive cohorts of deaf signers to acquire the language in its first decade. We find that as learners created new constructions to meet the new functions, they did not simply apply an already developed form more broadly, nor did they develop the more abstract application from the more iconic one. Instead, the more abstract who construction appears to have conventionalized first. Thus, the forms either emerged independently, or split very early in the 1980s, before either had developed as a consistently applied form.

Copyright $\odot 2010$ S. Karger AG, Basel
\end{abstract}

\section{Introduction: The Challenge of the Rich Language Environment}

In the typical case of language acquisition, a child is placed within a rich linguistic environment and comes to know many details about the surrounding language. Within a few years, thousands of words are acquired, along with an intricate

\section{KARGER}

Fax +4161306 1234

E-Mail karger@karger.ch www.karger.com (c) 2010 S. Karger AG, Basel

Accessible online at: www.karger.com/hde
Ann Senghas

Department of Psychology, Barnard College

3009 Broadway, New York, NY 10027 (USA)

Tel. +1 212854 0115, Fax +1 2128543601

E-Mail annie@alum.mit.edu 
system of grammatical devices that link the words together into complex structures like phrases and sentences. With a command of these devices, the child can extract highly abstract information from an utterance, such as whether a noun represents the subject or object of a verb, and whether multiple words - say, a pronoun, an adjective, and a noun - point to a single referent in the world. Where do such devices come from, both in the development of an individual learner, and in the history of a language? Do we start out with simple forms, that link in a direct way to simple functions, and build them into more complex forms to serve more abstract functions? As more complex constructions emerge, what determines the form they take? Specifically, how much do learners structure what they learn?

To address this question, we might follow the course of acquisition by an individual child, and as certain constructions appear in the language, determine whether complex, later-acquired structures seem to be built up from simpler, earlier-acquired ones. We would then look for patterns in the influence of the learner on the language, patterns that point to the nature of children's restructuring strategies.

However, such an approach soon arrives at a logical problem. Throughout the period when children are acquiring their language, they are exposed to adults using a mature form. We would expect a high degree of overlap between the patterns that would naturally result from children's learning mechanisms, and the patterns that appear in adult language. Indeed, adults were once children, applying the exact same mechanisms. Consider walking - children observe adults walking upright, and ultimately walk upright themselves. Noting the overlap between the adults' behavior and the child's will not inform us about the degree of environmental influence. Similarly, any imprint that children's biases would necessarily leave on language will already be reflected in the mature language that children hear every day. That is, any strong innate predispositions will also be evident in children's input.

Clouding the picture further, the history of mature languages results in elements that are shared by simple and complex constructions. As languages are passed down through the centuries, simple elements can become combined into a more complex form [Slobin, 2002], or a more complex form, over generations, may be reduced to a simple phonological element [van Gelderen, 2004]. As a child acquires the language in its modern state, what appears to be putting pieces together may instead represent the separate acquisition of historically related constructions, apparent patterns that are merely a reflection of the recycling of parts that took place during a language's path through history. For example, the expression going to can indicate movement to some location, as in 'I am going to the park', or it can indicate a future event that entails no movement at all, as in 'I am going to sing'. The two uses are clearly related historically, but a child may acquire them both successfully without building one from the other.

What this means for researchers is that when we observe a pattern in a child's language learning trajectory, we cannot know whether it is the natural contribution of this child learner, or of previous generations of child learners, or whether it entered the language some other way. Furthermore, because languages have been learned and relearned over generations, the impact of any one learner will be so small as to be immeasurable. These aspects of typical acquisition make it challenging to infer what information children take up as they acquire their language, and what operations they perform on that data. 
We can solve this logical puzzle by turning to cases in which the environment is not as rich as the typical case. What happens when learners are presented with much sparser language input, something that has not been built up and shaped by generations of learners like themselves? With the environment reduced, we can more easily observe the learners' contribution. The specific changes that take place can give us clues to where certain features of language originate, particularly those with their origins in the natural tendencies of child learners.

\section{An Atypical Language Environment}

A new sign language emerging within the deaf community in Nicaragua offers just the sort of atypical case that enables us to observe this process in action. Before the 1970s, deaf children in Nicaragua did not have access to any fully developed language. They could not hear the Spanish spoken around them, and there was no local sign language available. Societal attitudes kept most deaf individuals at home, and the few schools and clinics available served small numbers of children for short periods, with no contact outside school hours. As a result, deaf Nicaraguan children had minimal contact with each other, and no contact with deaf individuals older than themselves. In this context, no sign language emerged - a fact that is evident even today by the lack of language in adults over the age of 50 .

Then, in the late 1970s and early 1980s, rapidly expanding programs in special education brought deaf children and adolescents together in numbers greater than ever before [Polich, 1998; R.J. Senghas, 1997, 2003]. Deaf enrollment in the new programs initially comprised approximately 50 students in 1977, growing to over 200 by 1981, and increasing gradually throughout the 1980s to serve over 400 students yearly in elementary and vocational school [Polich, 2005]. The method of instruction aimed to teach students to lip-read and to speak Spanish, and had minimal success. Nevertheless, the children spontaneously began to use gestures to communicate with each other. As they interacted socially on school buses, in the schoolyard, and later in their homes, they converged on a common vocabulary of signs and conventions for stringing them together, and soon a new language was born. The language has continued to develop and change as new waves of children enter the community each year and learn to sign from older peers [A. Senghas, 1995]. Today there are approximately 1,000 signers of Nicaraguan Sign Language (NSL), ranging from 4 to 45 years of age.

The language environment in this case certainly was atypical, and particularly limited for the first group of children. The system of communication that emerged, however, is a natural human language, from its earliest stages. By natural, I mean that it arose naturally within a population of people using it to communicate, passing it on as they used it. They learned their language through the natural means of immersion and everyday use, not intentional construction and instruction. No one sat down and decided what NSL should be. No one planned a grammar and taught it to deaf children, through lessons in a classroom. NSL came into existence naturally, using natural learning devices. Consequently, it represents an imprint of the natural means by which humans learn and pass on language.

This history is not unique. Indeed, most, if not all, natural sign languages originated within social communities, and many have perpetuated themselves from one 
generation to the next within school environments, even as they traveled from one country to another [Padden and Humphries, 1988]. The sign language used in most of North America today is the result of a melding of local American signs with signs from France that spread through new schools established in the United States in the early nineteenth century. What we now call American Sign Language (ASL) has been passed down through generations of deaf schoolchildren ever since [Lane, 1984].

What is special about the Nicaraguan case is that the language emerged recently enough that its originators are still alive and available to provide samples of their signing, and that, by comparing them to younger signers today, we can measure the changes that resulted from each generation of learners. We can watch the language being born.

Because children entered the community steadily throughout the 1980 s and 1990s, deaf Nicaraguans today represent a continuum of the richness of the language environment they experienced as children. Recall that those who arrived in the earliest years encountered a new, fledgling system of signing, while those who arrived more recently encountered a richer, more developed language. This history has led to a community in which the richest, most fluent language users are the youngest members. We can discover the impact of each wave of learners by comparing different age cohorts of signers, progressing forward in time from older to younger signers.

Following this logic, in the studies described here, deaf participants are grouped according to the year that they joined the deaf community and learned to sign. To define two early periods in the history of this young language, we have divided the continuum of signers into two age cohorts, splitting them at the median. Accordingly, the first cohort includes those who arrived in the late 1970s and early 1980s; the second cohort includes those who arrived in the mid to late 1980s. All of the participants have been using NSL as their primary language for all of their lives, since they were 6 or younger, and therefore represent the best, most fluent signers of their generation. When the data were collected, the first-cohort signers were young adults in their 20s, and the second-cohort signers were adolescents.

\section{The Emergence of Two Uses for a Device}

In the present paper, we will consider a few studies that have captured some of the linguistic developments in NSL as it passed down through these cohorts. We will focus on a device that has become central to the language: a contrastive use of spatial modulations on signs, described below. This device has been applied to two primary functions in NSL. One is expressing the role of the participants in events, that is, indicating who. The other is describing the spatial locations and orientations of referents, that is, indicating where. We ask whether the who construction, which appears to be more abstract, derived from the where construction, which appears to be more basic and concrete, and closer to its gestural roots. Focusing on different uses for a single device enables us to capture the effects of successive cohorts of learners on an emerging grammar. How are elements reshaped from one form and function to another?

What we find, in the case of spatial modulations, is that children will not learn and reproduce the language of their environment faithfully if it is incomplete. If a fundamental function has no corresponding form of expression, a form will be found 
and applied in a new way, changing the language from that time onward. However, the changes captured here turn out not to be simply applying a form more broadly, to more functions, nor co-opting simpler forms wholesale for more abstract applications. Indeed, in this case, the more abstract application may have developed first.

\section{Spatial Modulations}

Developed sign languages around the world actively use the three-dimensional space in front of the signer for expressing grammatical relations. Many signs are produced in their neutral form in a central location in front of the signer. Modulating a sign's movement with respect to the signing space creates a non-neutral form with a marked change in meaning. Thus, a sign produced with a movement away from the body has a different meaning than a sign that moves toward the body. A sign that moves from left to right has a different meaning than a sign that moves from right to left. Spatial modulations serve a variety of grammatical functions, which vary from one sign language to another, including locative and temporal marking, indication of perspective, and anaphoric reference.

In many sign languages, spatial modulations are central to establishing the referents in a discourse and linking them to verbs, indicating what is called argument structure, showing who did something, and to whom. Nouns can be associated with particular locations in the signing space; verbs then 'agree' with their noun arguments by incorporating these same locations in some way, such as beginning or ending the verb there. For example, in British Sign Language, the same handshape is used for the verb in 'I ask him' and 'he asks me', but the movement and direction of palm orientation differs; crucially, in 'I ask him' the hand moves outward from the signer's body, toward some location, and in 'he asks me' the hand moves from that location toward the signer. By moving the verb toward or away from a specific location, the signer adds a spatial morpheme. Some agreeing verbs, such as the sign GIVE in ASL, can incorporate two spatial morphemes, beginning at the spot assigned to the subject, and ending at the spot assigned to the object [Adamo, Acuna, Cabrera, \& Lattapiat, 1999; Clibbens, 1998; Fischer \& Gough, 1978; Klima \& Bellugi, 1979; Meier, 1987; Meir, 1998; Padden, 1983; Supalla, 1982]. (For an alternative to this analysis of such constructions, see Liddell [2000].)

Other uses of spatial modulations are more iconic. One such use is locative marking, used in descriptions of physical spatial relations among objects, indicating where things are. For example, to describe objects arranged in a circle in ASL, the signs representing the objects would be produced in a circular arrangement in the signing space [Emmorey, 1996; Klima \& Bellugi, 1979]. To describe a book on a shelf, one hand, representing the book, would be placed above the other hand, representing the shelf. Although much of the form of such utterances is drawn from the structure of the world, even this use of space is not automatic or unambiguous [Emmorey \& Reilly, 1995]. Spatial signs can be interpreted only relative to other signs. A single movement might be simultaneously to the north, toward the door, or to the right of the signer. The interlocutor must be able to identify which interpretation of the movement is intended. Thus, for any spatial signing to be effective, interlocutors must have common, conventionalized devices that convey how space is being used in a particular utterance. 
Deaf Nicaraguans in the 1970s did not have access to a developed sign language that included conventionalized spatial devices. They would have had to draw on the use of space in the gestures that they saw, particularly any creative, productive gestures used to express relations between concepts. Hearing people exhibit some of the fundamental aspects of a spatial system when they use their hands to describe objects in unusual positions, or moving along various paths [Singleton, Goldin-Meadow, \& McNeill, 1995]. The rudimentary homesign systems that emerge in hearing families with a deaf child can also make use of the signing space, such as producing signs in particular locations to represent relationships among people, objects, and actions [Coppola, 2002; Goldin-Meadow \& Mylander, 1990]. Thus, some spatial resources were certainly available, and were good candidate raw materials for deaf Nicaraguans to develop devices for representing grammatical relations.

By documenting the early stages of NSL, we can capture the progression of spatial signing beyond these raw sources as its conventional, grammatical applications were established. Did one of the conventionalized uses serve as an intermediate step for the other? The more iconic, locative use of space for indicating where offers a possible precursor to the more abstract, argument structure use of space for indicating who. Indeed, many of the sign movements used to indicate the participants in an event appear to be metaphorically motivated by the spatial relationships among them [Casey, 2003; Taub, 2001]. For example, the ASL sign GIVE includes a movement away from the giver, toward a location associated with the recipient. This iconicity suggests that where came first. Early signers may have found that they could effectively communicate information about who participated in an event by pointing out where those participants were located. Then, as conventions were established for signing about where, they would have been available to apply to this new use of indicating who. Considering how spatial devices are used in mature languages, this account seems compelling. Now we have the opportunity to examine in an emergent language whether it is true.

\section{Spatial Modulations to Indicate Arguments}

In several studies, we have explored whether spatial modulations were used to indicate the participants in an event [Kegl, Senghas, \& Coppola, 1999; A. Senghas, 2003; A. Senghas \& Coppola, 2001; A. Senghas, Coppola, Newport, \& Supalla, 1997; R.J. Senghas, Senghas, \& Pyers, 2005]. That is, is the signing space used in a way that shows who did what to whom? For example, in a sentence that describes a man giving something to a woman, do signers use space to link the referents man and woman to the roles of giving and receiving?

One study specifically compared the first and second cohorts' production of such signs [A. Senghas et al., 1997]. Participants were shown videos depicting three actors, a man and two women, engaged in brief events, such as a man giving a cup to a woman, a woman giving a cup to a man, a man taking a ball from a woman, and so on. After watching each video clip, participants signed a simple sentence in NSL describing the event.

We expected signs to be modulated with respect to the body in ways that metaphorically matched the events, for example, GIVE moving away from the body, and TAKE moving toward the body. We were interested in whether the signing space is 


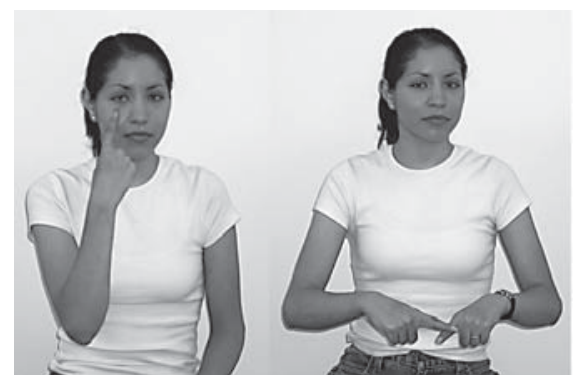

SEE

PAY

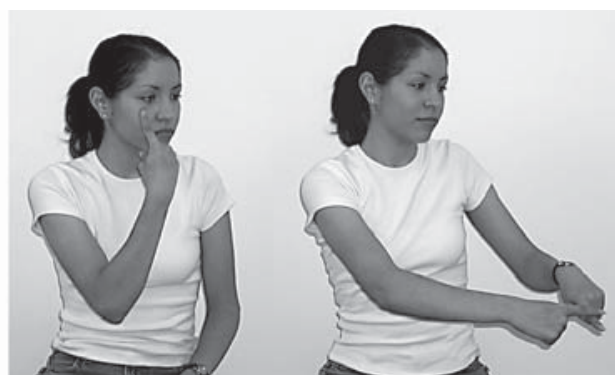

SEEleft
PAYleft

Fig. 1. a The signs SEE and PAY produced neutrally. $\mathbf{b}$ The signs SEE and PAY produced to the left.

differentiated further than this. Does producing a sign to the side differ in meaning from producing it in a neutral center? And even more specifically, once you have a discourse context with certain referents already established, is there a difference in meaning between signing to the left and signing to the right? Do such spatial movements distinguish referents from each other, and link them to verbs, tagged with their respective roles?

Our analyses revealed that only second-cohort signers produce movements toward non-neutral locations in a pattern that corresponds to the role of a referent. For example, modulating the verb to one side would link it to the recipient of a giving event, or the object of a looking event. Examples of this use of spatial modulation are shown in figure 1 . Here we see the Nicaraguan verbs SEE and PAY, produced with respect to neutral and non-neutral locations. In the non-neutral cases shown in figure $1 \mathrm{~b}$, the verbs' shared modulation (to the left) would indicate their link to a shared object. When produced by second-cohort signers, this sequence would mean that a single person was both seen and paid.

In order for such spatial modulations to effectively link grammatical elements across the discourse, a signer must use a consistent directional framework, or layout, across their sentences. The video clips that the signers watched all involved the same three actors, seated at a table facing the viewer. A signer linking each actor to a location in the signing space could do so in either of two ways. The signer could produce a representation using an unrotated layout, mirroring the layout on the screen (that is, the signer's right is mapped to the actors' left). Or, the signer could produce a layout rotated $180^{\circ}$ from his or her own perspective, matching the actors in the video (in this case, the signer's right is mapped to the actors' right). In the videos, the man was always seated on the left. Thus, signing that placed the man to the signer's left, as in the sign GIVE produced toward the left side when the man was the recipient, would represent an unrotated layout. Signing that represented the man to the right would represent a rotated layout (fig. 2).

We examined whether each signer maintained either of these two directional frameworks consistently across their responses. We found that the second-cohort signers consistently produced a rotated representation, both across the set of sentences by a signer, and across the group of signers. The older, first-cohort signers were 
Fig. 2. Illustration of unrotated and rotated representations of a giving event. The diagrams beneath the depiction of the event represent the signer and the signing area as viewed from above, with a semicircle representing the signing space in front of the signer. The movement of the verb is represented with an arrow, and the implied location of the man is marked with an X. This location is compared with the man's location in the event to determine the rotation of the representation (from Senghas [2003]).

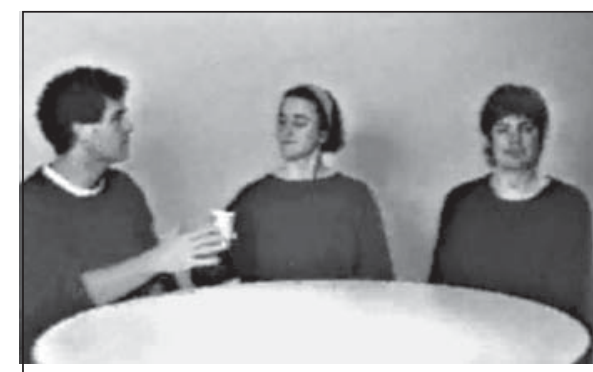

Stimulus event:

a woman giving a cup to a man

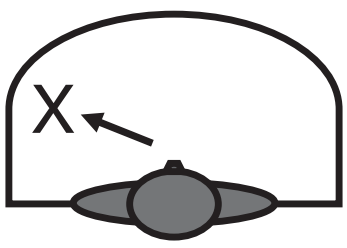

Unrotated representation

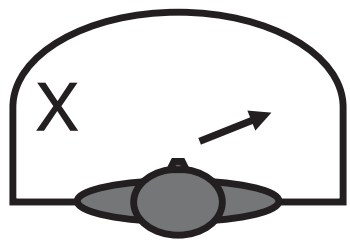

Rotated representation

not constrained in this way. They could produce signs in either direction, regardless of the role of a referent. For them, the construction in figure $1 \mathrm{~b}$ would therefore be equivalent to figure 1a. Both expressions would mean that someone was seen and someone was paid, but neither expression would indicate whether the arguments in those two expressions were shared. One person might have been both seen and paid, or perhaps one person was seen, and another paid. To a second-cohort signer, in contrast, the shared locations used by the verbs in figure $1 \mathrm{~b}$ could mean only that one and the same person was seen and paid. Lacking spatial co-reference in their interpretation, first-cohort expressions are less restricted in meaning than second-cohort expressions.

A similar difference between the first and second cohorts was observed in a comprehension study [A. Senghas, 2003]. Two years after they had produced the simple event descriptions for the production study above, signers were shown video clips of their own and other participants' signed sentences, and asked to point at pictures to indicate what these sentences could mean. The pictures were frame shots 
extracted from the action events, such as an image of a woman giving something to a man. All of the first-cohort signers interpreted the signed sentences they viewed in an unrestricted way; they did not limit their interpretation of the object of the verb (such as the recipient) based on the direction of the sign's movement. Accordingly, the same movement could mean a man giving something to a woman, or a woman giving something to a man. These signers identified such roles using word order, rather than the use of the signing space. In contrast, every second-cohort signer used the spatial aspects of a verb to restrict their interpretations of referents' roles. Right and left were not equivalent, and the interpretation of roles was restricted based on the direction of movement. Again, second-cohort signers all consistently applied a rotated layout as they linked verbs with referents across the set of sentences.

This difference between cohorts suggests that the spatial device for expressing the participants in events emerged in the mid 1980s, among those who were still children at the time, that is, the second cohort of signers. As this device conventionalized, it became possible to build other constructions that make contrastive use of the signing space. For example, an analysis of the use of pointing signs reveals that the use of pointing to indicate referent identity (as opposed to indicating locations) increased significantly over the same period [Coppola \& Senghas, 2010]. Such points can serve a pronoun-like function, coordinating with the spatial modulations to verbs, to indicate the argument structure of the sentence, and to co-index referents across discourse.

Where did these spatial modulations come from? They clearly were not present in the environment during the period when the first cohort was young and first developing the language, since that cohort still does not use them today, at least not for the function of indicating the participants of events. Evidently the first cohort produced a spatially neutral version of argument structure in NSL for the language's first 6 or 7 years. What this means is that the sign language they provided to the second cohort also did not include spatially marked forms, at least not for this function. So where did the second cohort get them? Gestures used in the general Nicaraguan environment would have been equally available to both cohorts, as would early regularities that appear in homesigns. What was available to the second cohort that was not available to the first? The answer is first cohort signing, from an early age. The second cohort must have taken something from the signing of the first cohort and reshaped it as they acquired it in a way that made them end up looking different from that very language model.

A clear candidate precursor to this abstract construction is the more concrete use of the signing space to describe physical spatial relations. When we look at the argument structure uses, the locations on different sides of the body are being mapped onto the various participants of events, often in a way that can be motivated by their relative locations in the world. We considered that these spatial modulations are not about argument structure in a linguistic sense, but are really just spatial signs for spatial relations. That is, perhaps the signs that we interpret as meaning the woman gave something to the man really mean to the right of the woman was a man and she gave something to her right. If this is true, the use of signs to indicate argument structure would represent a case of generalization, not grammaticization, more a case of the pragmatics of use than morphology. 

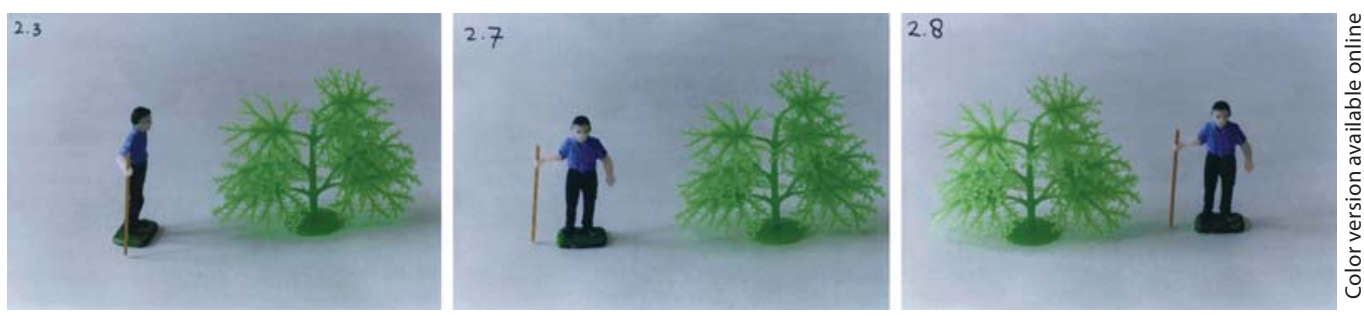

Fig. 3. Sample photos from the 'Man and Tree' task (Max Planck Institute).

This question motivates us to examine how Nicaraguans use the signing space to describe physical space, and compare it to the developments in argument structure. Have the two uses conventionalized in the same way with respect to directional framework, evidence that they may be a single device? Is the more concrete locative use found in the signing of the first cohort, providing evidence that it came first?

\section{Spatial Modulations to Describe Locative Relations}

In a few different studies, we have elicited signs for locative information, such as how two objects next to each other are arranged, or where an object is located in a room, or in the interior of a small box [Pyers, Shusterman, Senghas, Spelke, \& Emmorey, 2010]. It can be surprising how complex an operation it is to produce such descriptions, especially if a task requires successfully communicating spatial information to another signer. One study [A. Senghas, 2000, 2001] used a photo matching communication game developed at the Max Planck Institute for Psycholinguistics for comparing spatial constructions cross-linguistically [Pederson et al., 1998]. Participants play the game in pairs. They sit side-by-side, each facing an identical array of 12 photographs shielded from the other's view. The photos include a man and a tree in different relative positions and orientations. For example, in one photo the tree is to the viewer's right, and the man is to the left, seen in profile, facing the tree. In another, the tree is to the left, and the man is to the right, facing forward. Examples of these photos are shown below (fig. 3). One participant selects a picture and describes it to the other participant, who must then locate the matching picture in his or her own array. If the selection is correct, the photograph is set aside; if it is incorrect, it is returned to the array and the participants move to another trial. Participants are permitted to negotiate in their communication as needed, and to discuss their miscommunication when an incorrect picture is selected. The game continues until all of the pictures have been successfully eliminated.

To succeed at this task, the participants must share a common system for representing objects and their locations. They need to have common signs for the two objects in the photo; they must have a common use of the signing space to locate referents relative to each other, and they must have a common mapping between their spatial signs and physical locations in the world. 
Twenty Nicaraguan signers participated in this game; making up five pairs from each of the two cohorts. In producing their descriptions, the Nicaraguan signers drew from a set of constructions in NSL that can incorporate a spatial component. These included signs for MAN and TREE produced in different locations in the signing space, handshapes representing the objects produced in marked locations and orientations, as well as movements of the head and shoulders to show, with their bodies, the direction in which the man was oriented.

Though they used such spatial constructions, first-cohort signers lacked a systematic mapping between their signing space and the physical space they described. To describe a picture with a tree on the right, the sign TREE might be produced to the right (an unrotated representation); to describe another picture with the tree on the right, the sign TREE might be produced to the left (a rotated representation). There was not a consistent use of a directional framework from one first-cohort signer to the next, or even across the descriptions produced by a given signer. Of the 10 first-cohort signers, only one consistently applied a directional framework, which was an unrotated one. Furthermore, unlike the argument structure study, where many participants used word order devices, in this game there appeared to be no alternative, non-spatial means of communicating the critical information. As a result, there were many irresolvable miscommunications. First-cohort pairs selected matching pictures on only $52 \%$ of the trials.

Though the first-cohort signers struggled to negotiate effective descriptions of the pictures, it was clear that all of them could see and understand the differences between the photos. At the end of each trial, both participants would hold up their pictures, and would immediately acknowledge whether they were the same or different. None ever thought that a photo with a tree on the left looked the same as a photo with a tree on the right. Thus, the first-cohort signers could conceptualize the distinction between left and right, but most could not unambiguously express it, nor decipher it in the signing of their partners.

Second-cohort signers were more successful at communicating the spatial information, succeeding on $80 \%$ of the trials. All of them used spatial signs that effectively mapped onto the spatial relations in the photos. This included a differentiation in the signing space, such that signing to the left was used contrastively with signing to the right. More of the individual signers were consistent across photos in the directional framework that they used. Of the 10 second-cohort signers, four consistently used an unrotated layout, and two consistently used a rotated one. The remainder were not entirely consistent, though they tended to favor one layout. Even considering individuals' most frequent directional framework, they were not consistent as a group, with half preferring a rotated representation, and half preferring an unrotated representation (fig. 4). Because some pairs of signers had incompatible preferences (one member being a rotator and the other a non-rotator), many of the errors occurred early in the game, followed by some negotiation about how the signing space was being used. The negotiations were similar to English speakers' saying 'Oh, no, not that way - when I say 'right', I mean my right.'

Two of the 'incompatible' pairs of second-cohort signers were sets of best friends who had been signing together since they first met in school at the age of 4 or 5 . They were very surprised to discover that they were not understood at first when describing the locations of the man and tree. None of these four signers had ever noticed anything about their partner's signing that was different from their own. Even these 


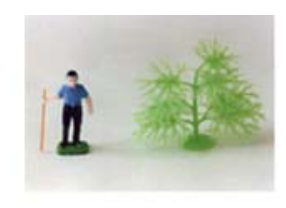

Stimulus photo

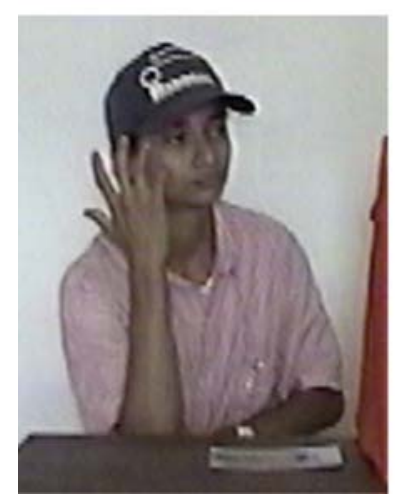

Unrotated representation

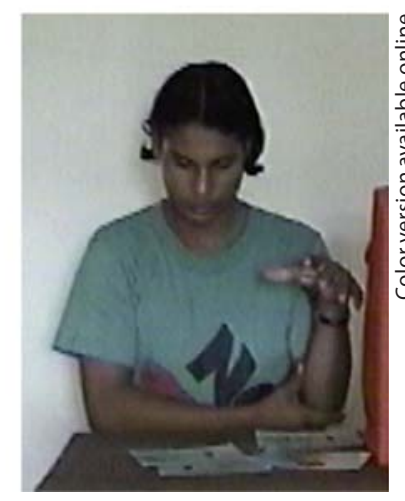

Rotated representation

Fig. 4. Examples of unrotated and rotated representations of the location of the tree in the 'Man and Tree' game. The pair of participants shown are second-cohort signers who have been best friends since a young age. Each one is presented describing the same picture, in which the tree is on the right side. The unrotated representation places the tree to the signer's right; the rotated representation places it to the signer's left.

pairs, with over 10 years of constant contact, had not converged on common spatial framework in their representations.

Apparently, the fairly direct and more concrete use of spatial modulation for indicating where had not conventionalized as much as spatial modulations used to indicate who. Recall that when indicating the participants of events, second-cohort signers consistently produced and interpreted signs using a rotated representation. Thus, for approximately half of second-cohort signers, the rotation that they prefer differs for the two uses: they use a rotated representation to show who, and an unrotated representation to show where.

\section{Evidence for Separate Spatial Constructions}

Though there are many similarities in the spatial devices used for argument structure and for locative expressions, we can conclude that the two uses do not represent a single construction type. Indicating who participated in an event is not a metaphorical translation of where they stood in relation to each other. In the language of the second cohort of signers, both constructions make use of a productive mapping between the signing space and real-world space. However, for argument structure this mapping is consistently realized with a rotated representation, while 
for locative expressions it can be realized with a rotated or unrotated one, depending on the signer, and not consistently for all signers.

We do not doubt that both uses have their origins in gestural reference to the locations of people and things. It is no surprise that we might describe something that is to someone's right with a gesture to the right. Such spatial reference was unquestionably adopted into the homesign systems that predated and fed into NSL [Coppola \& Senghas, 2010]. It may even be the case that the argument structure constructions initially adopted wholesale the forms used to describe spatial relations. That is, there may very well have been a time when she gave to him was expressed with a construction meaning she gave to the right.

Even if these ever were a common construction, the two uses must have diverged by soon after 1983, when the second cohort arrived. Since that time, the argument structure use appears to have conventionalized a little bit more quickly than the locative use, settling on a rotated representation. The locative use, on the other hand, still does not have a standardized, conventional directional framework.

Perhaps it never will. It may be that the more concrete, iconic use of spatial representation is subject to less pressure to conventionalize, since one is often able to point to objects and locations in the real world to disambiguate such descriptions. People are typically already familiar with the relative locations of objects that are being discussed within locative constructions, and signers rarely have to grammatically distinguish spatial layouts that are mirror images of each other. Consequently, miscommunications of the sort observed in our experiments rarely occur in everyday interactions. Argument structure, in contrast, is communicated at a much more abstract level, and cannot be as easily disambiguated by shared knowledge. If a spatial modulation could mean he gives to her as easily as it could mean she gives to him, it would not provide any information about the referents' respective argument roles. A spatial modulation can be effective as a device for indicating argument roles only if communication partners have perfect parity with respect to how directional movements are to be encoded and decoded. They cannot look to the physical environment to fill in the gaps.

\section{The Creative Power of Child Learners}

We have shown that in the early years of NSL, a generation of children who were exposed to language input that offered no regular morphological marking of argument structure roles nevertheless ended up producing a language that did mark such roles.

Evidently, learners acquiring the language had an expectation that this function would be encoded in their language, and this expectation prevented them from learning the language faithfully. For this group, language learning did not entail reproducing the patterns that they observed in the signing of their older peers. Instead, they likely looked for some other aspect of the language environment that could be applied to the missing function.

Where did they look? One might expect, given the similarities between the constructions today, that learners co-opted earlier-emerging locative expressions and applied their form directly to argument structure functions. The findings discussed here suggest that this did not happen. The spatial conventions of the two construc- 
tion types are incompatible. Interpreting one with the conventions of the other can result in sentences conveying the opposite of the intended meaning.

On the other hand, one might suppose that learners took a gestural form commonly used by the Spanish speakers that surrounded them, and adopted it into the sign language for this purpose. This, too, is unlikely, since any common gestural patterns would have been equally available to both the first and second cohorts, and we find the argument structure forms emerged in the signing of the second cohort only. Evidently, the gestures produced by hearing people that all of the deaf Nicaraguans observed are not rich or systematic enough to apply to this function directly.

There must have been some intermediate use of spatial signing, not as raw a source as common gestures, but not as set as the locative constructions of mature sign languages, that could be systematized and employed to indicate argument roles. In this case, spatial signing in the input that included information about where people were may have coincided with indications of who participated in an event, making it possible to reanalyze spatial signs with an eye to semantic role. Pressure to systematize the who constructions could have led to regularities in the use of space for them, but left where constructions unaffected. At least one person would need to have reanalyzed the input this way, but it certainly could have been more.

This intermediate use need not have been systematic in the selection of rotation within the directional framework. There might have been a tendency to produce rotated representations slightly more than unrotated ones, just enough to tip the balance for new learners to produce a consistently rotated representation once the form was repurposed. This would be similar to the previously reported case of a deaf child learning ASL from parents who learned to sign late in life, as adolescents. Though the parents' productions were irregular and unsystematic, the child treated many constructions as if they exhibited more consistency than they did, and his production was much more regular and native-like [Singleton \& Newport, 2004].

Whatever the source of the form, its reanalysis did not happen in a single iteration of learning, the way an individual learns a language. Rather, it required at least two generations of learners. The stage of signing seen in the first cohort apparently needed to emerge first, making expressive use of the signing space, even if in an inconsistent way. Members of the second cohort, observing such signs, could then interpret spatial movements as if they marked more than they did, as if they had more consistency than they did, and even end up analyzing them into two different kinds of linguistic constructions.

Once introduced, the new mappings of form to function could spread rapidly through the community, one dyadic interaction after another. However, not everyone acquired this new way of indicating who. In peer conversations, the influence was bidirectional. That is, each child could influence, and be influenced by, his or her age peers, resulting in horizontal convergence across members of the age cohort. However, along the vertical dimension, signers did not converge. Deaf adolescents in the mid 1980s, even those who had been signing since they were young children, did not acquire the new construction, despite frequent contact with younger signers. Thus, the feature did not spread from the second cohort up to the first. Evidently, language changes are passed only from older to younger signers.

Why this unidirectional flow? Logically, exposure must be equivalent in both directions along the vertical dimension. Adolescents are in contact with children just 
as much as children are in contact with adolescents. The fact that they respond differently to the information shared during that contact points to a change with age in the ability to learn, and even create, language. Consequently, once a language is passed from adolescents to children, it does not look back.

In a similar vein, though two constructions may have a common origin, they do not necessarily retain their connection. Once the functions of indicating argument roles and indicating locative relations took on distinct forms of spatial signing, they evolved independently. As new signers converged on the form of each, they no longer automatically transferred developments from one domain to the other. Following the split, representations for indicating argument roles could become consistently rotated without affecting the form of signs used to express locative relations.

We cannot know where new generations will take NSL, and we cannot predict with confidence which of today's developments will remain tomorrow. But as each subsequent wave of children rebuild and restructure it, we can look back at the course that the language has taken. When we do so, we may be surprised at the changes we observe. What seemed an obvious progression from simple to complex, from concrete to abstract, may represent our own reconstruction rather than theirs.

\section{Acknowledgments}

Research described in this paper was supported by the Language and Cognition Group at the Max Planck Institute for Psycholinguistics, award R01 DC00167 to Elissa Newport and award R01 DC05407 to the author from the National Institute on Deafness and Other Communication Disorders (NIDCD), National Institutes of Health (NIH). The content is solely the responsibility of the author and does not necessarily reflect the views of the funding institutions.

\section{References}

Adamo, D., Acuna, X., Cabrera, I., \& Lattapiat, P. (1999). Verbos espaciales locativos en la lengua de señas chilena. Revista de lingüística teórica y aplicada, 37, 7-21.

Casey, S. (2003). 'Agreement' in gestures and signed languages: The use of directionality to indicate referents involved in actions. Unpublished PhD dissertation, University of California, San Diego.

Clibbens, J. (1998). The development of spatial reference in British Sign Language. Deafness and Education, 22, 18-23.

Coppola, M. (2002). The emergence of grammatical categories in homesign: Evidence from family-based gesture systems in Nicaragua. Unpublished $\mathrm{PhD}$ dissertation, University of Rochester, Rochester.

Coppola, M., \& Senghas, A. (2010). Deixis in an emerging sign language. In D. Brentari (Ed.), Sign languages: A Cambridge language survey (pp. 543-569). Cambridge: Cambridge University Press.

Emmorey, K. (1996). The confluence of space and language in signed languages. In P. Bloom, M. Peterson, L. Nadel \& M. Garrett (Eds.), Language and space (pp. 171-209). Cambridge: MIT Press.

Emmorey, K., \& Reilly, J.S. (1995). Language, gesture, and space. Hillsdale: Erlbaum.

Fischer, S., \& Gough, B. (1978). Verbs in American Sign Language. Sign Language Studies, 18, 14-48.

Goldin-Meadow, S., \& Mylander, C. (1990). Beyond the input given: The child's role in the acquisition of language. Language, 66, 323-355.

Kegl, J., Senghas, A., \& Coppola, M. (1999). Creation through contact: Sign language emergence and sign language change in Nicaragua. In M. DeGraff (Ed.), Language creation and language change: Creolization, diachrony, and development (pp. 179-237). Cambridge: MIT Press.

Klima, E., \& Bellugi, U. (1979). The signs of language. Cambridge: Harvard University Press.

Lane, H. (1984). When the mind hears: A history of the Deaf. New York: Random House.

Liddell, S.K. (2000). Indicating verbs and pronouns: Pointing away from agreement. In K. Emmorey \& $\mathrm{H}$. Lane (Eds.), The signs of language revisited: An anthology to honor Ursula Bellugi and Edward Klima (pp. 303-320). Mahwah: Erlbaum. 
Meier, R.P. (1987). Elicited imitation of verb agreement in American Sign Language - Iconically or morphologically determined? Journal of Memory and Language, 26, 362-376.

Meir, I. (1998). Syntactic-semantic interaction in Israeli sign language verbs: The case of backwards verbs. Sign Language \& Linguistics, 1, 3-37.

Padden, C. (1983). Interaction of morphology and syntax in American Sign Language. Unpublished PhD dissertation, University of California, San Diego.

Padden, C., \& Humphries, T. (1988). Deaf in America: Voices from a culture. Cambridge: Harvard University Press.

Pederson, E., Danziger, E., Wilkins, D.P., Levinson, S.C., Kita, S., \& Senft, G. (1998). Semantic typology and spatial conceptualization. Language, 74, 557-589.

Polich, L. (1998). Social agency and deaf communities: A Nicaraguan case study. Unpublished PhD dissertation, University of Texas at Austin.

Polich, L. (2005). The emergence of the deaf community in Nicaragua: 'With sign language you can learn so much'. Washington: Gallaudet University Press.

Pyers, J.E., Shusterman, A., Senghas, A., Spelke, E.S., \& Emmorey, K. (2010). Evidence from an emerging sign language reveals that language supports spatial cognition. Proceedings of the National Academy of Sciences, 107, 12116-12120.

Senghas, A. (1995). Children's contribution to the birth of Nicaraguan Sign Language. Unpublished PhD dissertation, Massachusetts Institute of Technology, Cambridge.

Senghas, A. (2000). Differences between first- and second-cohort Nicaraguan signers in communicating location and orientation. Poster presented at the Seventh International Conference on Theoretical Issues in Sign Language Research (TISLR7), Universiteit van Amsterdam, Amsterdam.

Senghas, A. (2001). The emergence of grammatical devices for indicating location and orientation in Nicaraguan Sign Language. Paper presented at the Twenty-Sixth Annual Boston University Conference on Language Development (BUCLD26).

Senghas, A. (2003). Intergenerational influence and ontogenetic development in the emergence of spatial grammar in Nicaraguan Sign Language. Cognitive Development, 18, 511-531.

Senghas, A., \& Coppola, M. (2001). Children creating language: How Nicaraguan Sign Language acquired a spatial grammar. Psychological Science, 12, 323-328.

Senghas, A., Coppola, M., Newport, E.L., \& Supalla, T. (1997). Argument structure in Nicaraguan Sign Language: The emergence of grammatical devices. In E. Hughes, M. Hughes, \& A. Greenhill (Eds.), Proceedings of the 21st Boston University Conference on Language Development (pp. 550 561). Boston: Cascadilla Press.

Senghas, R.J. (1997). An 'unspeakable, unwriteable' language: Deaf identity, language and personhood among the first cohorts of Nicaraguan signers. Unpublished PhD dissertation, University of Rochester, Rochester.

Senghas, R.J. (2003). New ways to be deaf in Nicaragua: Changes in language, personhood, and community. In L. Monaghan, K. Nakamura, C. Schmaling \& G.H. Turner (Eds.), Many ways to be deaf: International, linguistic, and sociocultural variation (pp. 260-282). Washington: Gallaudet University Press.

Senghas, R.J., Senghas, A., \& Pyers, J.E. (2005). The emergence of Nicaraguan Sign Language: Questions of development, acquisition, and evolution. In J. Langer, C. Milbrath \& S.T. Parker (Eds.), Biology and knowledge revisited: From neurogenesis to psychogenesis (pp. 287-306). Mahweh: Erlbaum.

Singleton, J.L., Goldin-Meadow, S., \& McNeill, D. (1995). The cataclysmic break between gesticulation and sign: Evidence against a unified continuum of gestural communication. In K. Emmorey \& J.S. Reilly (Eds.), Language, gesture, and space (pp. 287-311). Hillsdale: Erlbaum.

Singleton, J.L., \& Newport, E.L. (2004). When learners surpass their models: The acquisition of American Sign Language from inconsistent input. Cognitive Psychology, 49, 370-407.

Slobin, D.I. (2002). Language evolution, acquisition and diachrony: Probing the parallels. In T. Givon \& B.F. Malle (Eds.), The evolution of language out of pre-language (pp. 375-392). Amsterdam: Benjamins.

Supalla, T. (1982). Structure and acquisition of verbs of motion and location in American Sign Language. Unpublished PhD dissertation, University of California, San Diego.

Taub, S. (2001). Language from the body: Iconicity and metaphor in American Sign Language. Cambridge: Cambridge University Press.

van Gelderen, E. (2004). Grammaticalization as economy. Amsterdam: Benjamins. 